SANDIA REPORT

SAND2004-8208

Unlimited Release

Printed April 2004

\title{
Large Batch Dimensional Metrology Demonstrated in the Example of a LIGA Fabricated Spring
}

Georg Aigeldinger, Joseph Ceremuga, Dawn Skala

Prepared by

Sandia National Laboratories

Albuquerque, New Mexico 87185 and Livermore, California 94550

Sandia is a multiprogram laboratory operated by Sandia Corporation,

a Lockheed Martin Company, for the United States Department of Energy's

National Nuclear Security Administration under Contract DE-AC04-94AL85000.

Approved for public release; further dissemination unlimited.

\section{Sandia National Laboratories}


Issued by Sandia National Laboratories, operated for the United States Department of Energy by Sandia Corporation.

NOTICE: This report was prepared as an account of work sponsored by an agency of the United States Government. Neither the United States Government, nor any agency thereof, nor any of their employees, nor any of their contractors, subcontractors, or their employees, make any warranty, express or implied, or assume any legal liability or responsibility for the accuracy, completeness, or usefulness of any information, apparatus, product, or process disclosed, or represent that its use would not infringe privately owned rights. Reference herein to any specific commercial product, process, or service by trade name, trademark, manufacturer, or otherwise, does not necessarily constitute or imply its endorsement, recommendation, or favoring by the United States Government, any agency thereof, or any of their contractors or subcontractors. The views and opinions expressed herein do not necessarily state or reflect those of the United States Government, any agency thereof, or any of their contractors.

Printed in the United States of America. This report has been reproduced directly from the best available copy.

Available to DOE and DOE contractors from

U.S. Department of Energy

Office of Scientific and Technical Information

P.O. Box 62

Oak Ridge, TN 37831

Telephone: (865)576-8401

Facsimile: (865)576-5728

E-Mail: $\quad$ reports@adonis.osti.gov

Online ordering: http://www.doe.gov/bridge

Available to the public from

U.S. Department of Commerce

National Technical Information Service

5285 Port Royal Rd

Springfield, VA 22161

Telephone: (800)553-6847

Facsimile: (703)605-6900

E-Mail: orders@ntis.fedworld.gov

Online order: http://www.ntis.gov/help/ordermethods.asp?loc=7-4-0\#online

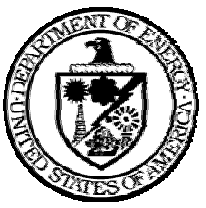


SAND2004-8208

Unlimited Release

Printed April 2004

\title{
Large Batch Dimensional Metrology Demonstrated in the Example of a LIGA Fabricated Spring
}

\author{
Georg Aigeldinger and Joseph T. Ceremuga \\ Microsystems Processing Department \\ Sandia National Laboratories / California \\ and \\ Dawn M. Skala \\ Advanced Lithography Department \\ Sandia National Labortories / California
}

\begin{abstract}
Deep x-ray lithography in combination with electroforming is capable of producing high precision metal parts in small lot series. This study deals with a high aspect ratio structure with overall dimensions on the order of $10 \mathrm{~mm} \times 7 \mathrm{~mm} \times 1.5 \mathrm{~mm}$, with the smallest line width being $150 \mu \mathrm{m}$. The lateral deviation from the design is to be kept to a minimum, preferably below $5 \mu \mathrm{m}$. To ensure adequate quality control, a semi-automated metrology technique has been established to measure all parts.

While the paper will give a brief overview of all involved techniques, it focuses on the method to measure the top and bottom of the parts and the top of geometries following the process. The instrument used is a View Engineering Voyager V6x12 microscope, which is fully programmable. The microscope allows direct measurement of geometries but also is capable of saving all captured data as point clouds.

These point clouds play a central role when evaluating part geometry. After measuring the part, the point cloud is compared to the computer aided design (CAD) contour of the part, using a commercially available software package. The challenge of proper edge lighting on a nickel alloy part is evaluated by varying lighting conditions systematically. Results of two conditions are presented along with a set of optimized parameters. With the introduced set of tools, process flow can be monitored by measuring geometries, e.g. linewidths in every step of the process line. An example for such analysis is given. After delivery of a large batch of parts, extensive numbers of datasets were available allowing the evaluation of the variation of part geometries. Discussed in detail is the deviation from part top to part bottom geometries indicating swelling of the PMMA mold in the electroplating bath
\end{abstract}




\section{Acknowledgements}

The authors would like to thank Stewart Griffiths and Jeff Crowell from Sandia National Laboratories for providing FEM analysis for PMMA geometries and Nancy Yang, Sandia National Laboratories, for supplying SEM graphs of typical LIGA part crossections.

All x-ray lithography exposures for the fabrication of the first build of LIGA springs have been conducted at the Advanced Light Source, Berkeley, CA. The Advanced Light Source is supported by the Director, Office of Science, Office of Basic Energy Sciences, Materials Sciences Division, of the U.S. Department of Energy under Contract No. DEAC03-76SF00098 at Lawrence Berkeley National Laboratory 


\section{Large Batch Dimensional Metrology Demonstrated in the Example of a LIGA Fabricated Spring}

\section{Introduction}

Deep X-ray lithography along with electroforming, is capable of producing high precision parts with high aspect ratio [1]. The method of directly using the synchrotron mold for part production has generally been called „direct LIGA“ [2]. LIGA is a German acronym for lithography, electroforming and molding. Parts created by direct LIGA may have very unusual metrology challenges since lateral dimensions must be held very tightly, sometimes just several micron tolerances on millimeter to centimeter scale parts. The height of the part also complicates the dimensioning since techniques used in the semiconductor or silicon MEMS area are not directly applicable. With one exception [3], past work involving metrology in the LIGA process has mainly focused on thermal mask distortions and resulting errors [4], polymethylmethacrylate (PMMA) offsets and overall patterning accuracy [5-8], and PMMA swelling during processing and electroforming [9]. The presented work dimensionally quantifies lots of released direct LIGA metal parts which comprise all of the above process effects and relates them to part specifications. Repeatability and accuracy of processes used to define the parts can be addressed in this way.

Figure 1 shows a principal sketch of a typical electroplated, lapped, polished and released metal part made by direct LIGA. Different features of the part, which are of interest for metrology, are indicated. Table 1 summarizes the methods and instrumentation used for capturing the dimensions of a typical released LIGA part: XY feature size and part size dimensioning on the top (lapped and polished) and bottom (released) surface is achieved using optical measuring microscopes. While other methods like scanning electron microscopy (SEM) and atomic force microscopy (AFM) are available and may be able to offer higher precision than optical microscopy, those instruments are not feasible for measuring larger quantities of prototypes. 


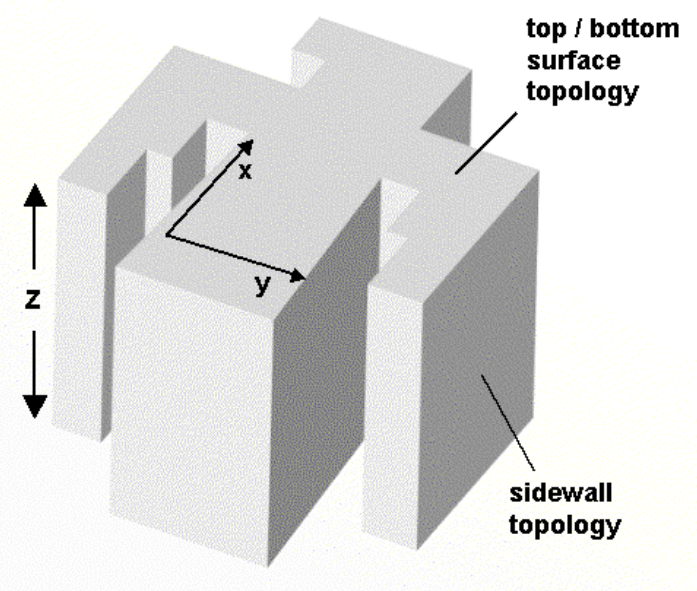

Figure 1: Principal sketch of an electrodeposited, lapped and released single LIGA part. Shown are the dimensions and areas of interest for inspecting such a part.

\begin{tabular}{|l|rl|}
\hline Dimension of Interest & Instruments used for measurement \\
\hline XY dimensions & $\bullet$ & View Engineering Microscope \\
& & Voyager V6x12 \\
& $\bullet$ & Nikon MM-40 Microscope \\
\hline Z heights & $\bullet$ & Indicator over base (Heidenhain CP25M) on \\
& & large samples. \\
& $\bullet$ & Wyco NT3300 Interferometric Microscope on \\
& & small and fragile samples. \\
& $\bullet$ & Voyager and Nikon Microscopes (focus) \\
& $\bullet$ & Wyco NT3300 Interferometric Microscope \\
Topologies & $\bullet$ & SEM (side views and cross sections) \\
(Sidewall, Top \& & $\bullet$ & Tencor / Dektak contact profilometers \\
Bottom) & &
\end{tabular}

Table 1: Dimensions of interest and the tools used to quantify them.

The thickness $\mathrm{Z}$ of the part is determined mechanically, using a high precision indicator over base. This method is reliable and trouble free for large, fairly rugged and easy to handle parts that can be sampled in several areas, for example the LIGA spring described in the next paragraph. For more fragile and or smaller parts, e.g. LIGA fabricated acceleration sensors [10], an interferometric microscope is used. The instrument can capture the height of a distortion free part by scanning from its top to the bottom, where it is placed on an optically flat surface. In certain cases one may choose to measure thickness with the optical microscopes, reading the $\mathrm{Z}$ height and using the fact that, at high magnifications, the depth of focus is limited to only a few micrometers.

Sidewall topologies are measured using white light interferometry. On samples that have complicated shapes like the LIGA spring, access to sidewalls for measurement is 
complicated. Special fixtures that hold parts on their side can be fabricated to sample outside surfaces of structures. In addition, metrology features that carry all aspects of the actual part are created on the same x-ray mask. These test features can then be examined and general sidewall information can be applied to the entire wafer.

Figure 2 shows a batch of LIGA fabricated springs. The PMMA mold is patterned using synchrotron radiation and nickel manganese is electroplated into the mold. After parts are lapped and polished to the desired height, they are released from the substrate using a sacrificial layer. The released parts are then dimensionally characterized. The specifications for these springs call for a height of $(1500 \pm 10) \mu \mathrm{m}$, with the smallest lateral feature width being $(150 \pm 5) \mu \mathrm{m}$, translating to a maximum aspect ratio of 10 . The part has an overall lateral dimension on the order of $1 \mathrm{~cm}$. Specifications call out a contour on the entire part of $5 \mu \mathrm{m}$. To capture such a large lateral size while holding sufficient measurement accuracy is only possibly by combining high magnification precision edge finding with precision lateral movement to capture the entire part geometry [11].

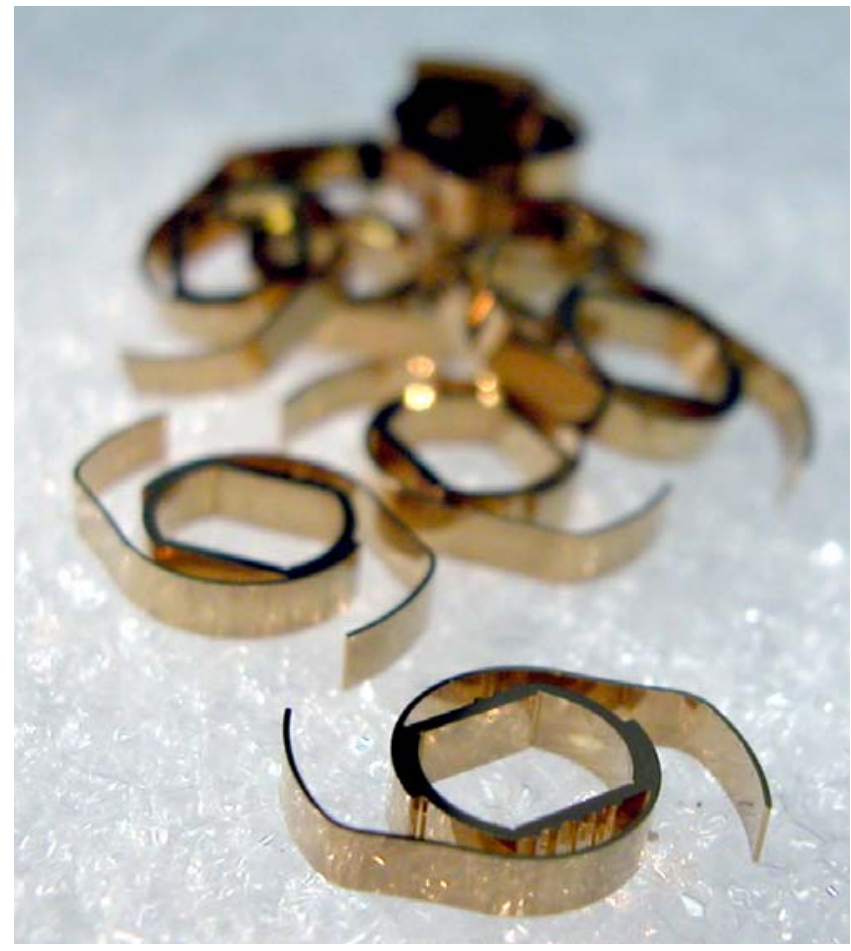

Figure 2: Batch of LIGA springs. These springs are electroplated nickel manganese alloy that is gold coated. The height of these springs is $1500 \mu \mathrm{m}$ with $150 \mu \mathrm{m}$ thick arms. The lateral dimension is on the order of one square $\mathbf{c m}$.

\section{Experimental}

The View Engineering's Voyager optical microscope used is fully programmable to position edge finders automatically and to capture measurements of entire wafers [12]. Lighting options include coaxial, ring lighting, backlighting, and combinations of these. The optics chosen for LIGA scale measurements include 10, 20 and $50 \mathrm{X}$ objectives which result in approximately 1.0, 0.5 and $0.2 \mu \mathrm{m}$ pixel size on the CCD camera and video screen. The instrument's software uses advanced edge finding algorithms, 
including sub-pixelation. This results in repeatability - on chrome on glass $150 \mu \mathrm{m}$ features - of better than $0.3 \mu \mathrm{m}$. This edge finding capability is combined with a motion stage that covers an area of $15 \mathrm{~cm}$ by $30 \mathrm{~cm}$. The repeatability of the motion stage has been measured to be better than $1 \mu \mathrm{m}$ over the full range.

The microscope directly determines simple geometries and is capable of saving raw point clouds of entire parts. In the direct measurement of geometries, simple shapes like radii, linewidths, and lengths can be captured and saved to file. For the LIGA spring, body widths, arc diameters and arm widths are measured in this mode. When capturing the part by saving point clouds, the instrument saves all points found using the edge finders programmed by the user. The point clouds in the example of the contact spring are over 4000 points per part. Entire wafers can be captured, resulting in point clouds of over 100,000 points.

While the respectabilities and capabilities of the instrument are very encouraging, there are challenges that come with measuring high aspect ratio metal parts. It is well known from literature, that LIGA is capable of creating microstructures in PMMA with sub micrometer features and precision [6]. Fabrication of direct LIGA metal parts requires a planarization step on the top surface. The bottom surface may be separated by a chemical etch on a sacrificial metallization layer, which is the current approach here, or a backside grinding and lapping process. Both of these processes yield nickel parts with „rounded“ edges. Figure 3 shows a typical cross section of a lapped top edge of a released LIGA part. It is evident from the figure that the structure has a definite radius, making top down edge detection difficult. To minimize the impact of this radius on edge detection, extensive studies are being undertaken to systematically improve lighting conditions.

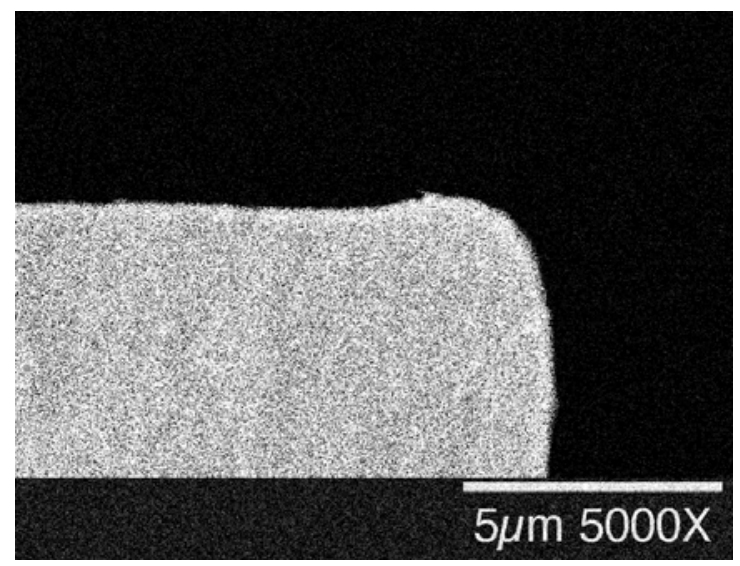

Figure 3: SEM picture of a cross section through a typical lapped nickel part. Note the rounded top edge.

Two general lighting conditions are introduced here, top lighting and side lighting. A common way to light a structure is to light it from the top, using the coaxial light source of the microscope as in Figure 4a. With this method, focus on the top surface can be assured. However, the top light gives a diffuse edge that tends to propagate into the part. Intuitively this edge seems to be too far into the part solid. Figure 5a shows a video screen with the typical edge found by the software with top coaxial lighting. Light falling in from the top is reflected away on the rounded edge of the nickel part. In terms of 
structure width, this means that the width measured will be too small as indicated in Figure 4a (length $\mathrm{X}$ ).

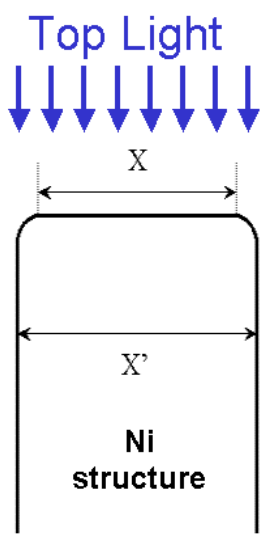

a)

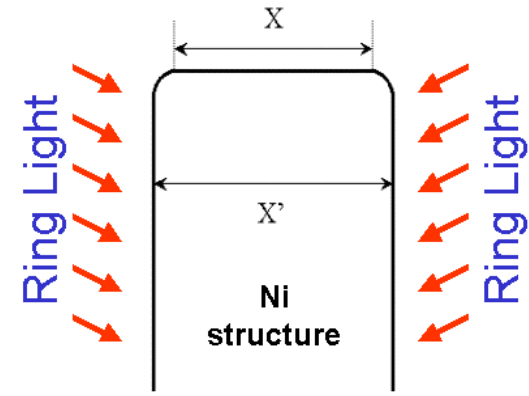

b)
Figure 4: Different lighting options on the View microscope: a) top light leading to a slight narrow measurement $(\mathrm{X})$ and $\mathrm{b})$ ring light, leading to a larger, likely more precise measurement of true structure width $X^{\prime}$.

The other lighting option discussed, uses an LED ring light that brings light in from the side as shown in the principal sketch in Figure 4b. This lighting condition results in the opposite tone, with the nickel structure now being dark and the open area bright as shown in Figure 5b. The edge is more defined (less scatter) and it shows to be further "out" from the material. Studies where the same part geometry was measured 25 times in 105 locations showed that this edge is typically $2.5 \mu \mathrm{m}$ further outside from the part solid. This result is encouraging and the true structure edge may be found as it is indicated as $\mathrm{X}^{\prime}$ in Figure 5b. Current work is being conducted where gauge blocks are prepared like LIGA parts, to establish a true high aspect ratio part calibration for this edge finding scenario.

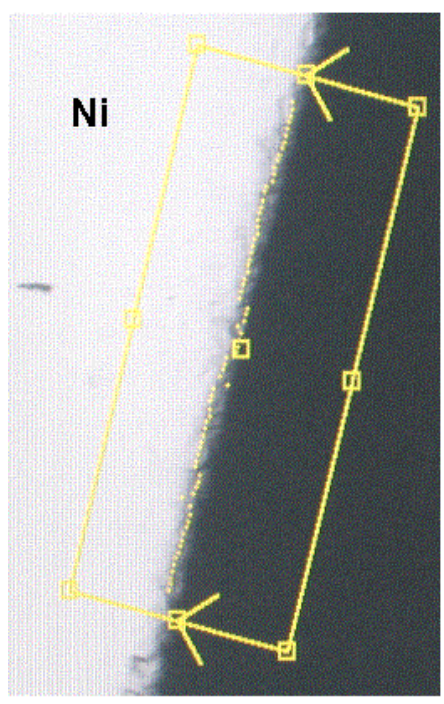

a) Top Light

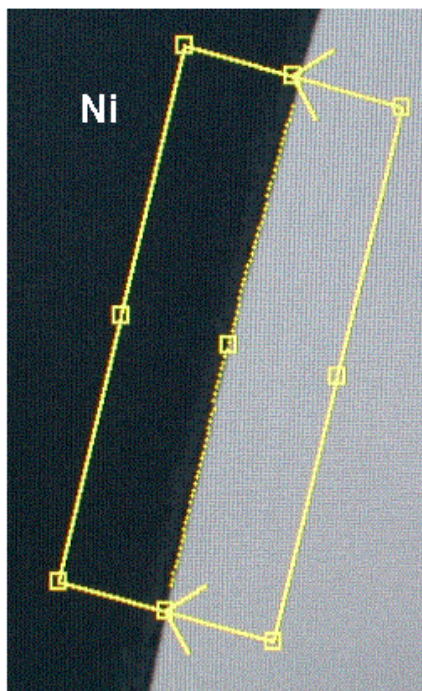

b) Ring Light
Figure 5: Screen views of View Engineering voyager microscope when using a) top light and b) ring light. 


\section{Example: Linewidths in Process steps}

Measurements can be taken of the final part for quality control as well as during the process. For example, the arms of the LIGA spring are sampled for linewidths in 10 positions on each arm as indicated in Figure 6.

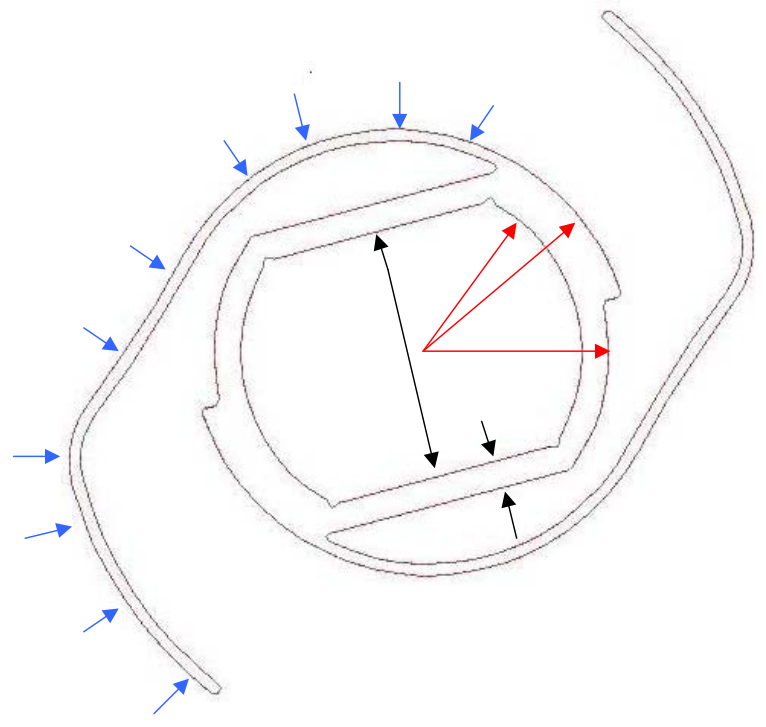

Figure 6: Simple geometries measured on the LIGA spring are linewidths, body widths and arc radii.

Figure 7 shows the line widths measured in chrome on glass, X-ray mask, developed PMMA mold, nickel parts unreleased and nickel parts released (top and bottom of part). This is using a nominal linewidth of $150 \mu \mathrm{m}$. This fabrication run is an R\&D effort using SU-8 as a resist to create very thick absorber X-ray masks. It can clearly been seen that the copy step from the X-ray mask into the PMMA leads to a linewidth decrease of over $5 \mu \mathrm{m}$. This effect indicates that the Au mask absorber is out of tolerance. Likely, a sloped sidewall in the Au absorber or underplating lead to the deviation, i.e., the measured top edge of the Au absorber is not the outer edge of the Au absorber defining the open area to be exposed. 


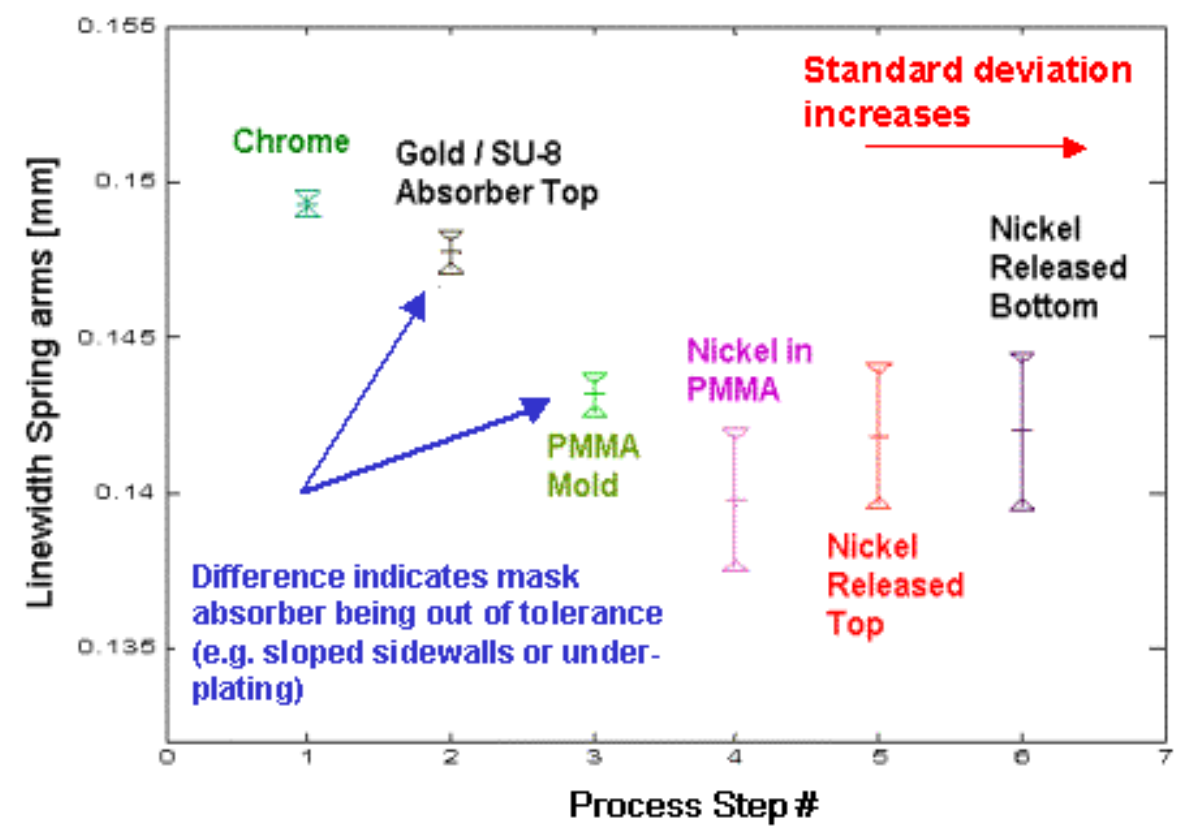

Figure 7: Linewidth of spring arms in a fabrication run as it evolves through all process steps.

Another interesting aspect Figure 7 is the fact that the standard deviation increases with every process step. Two factors play into this effect. First, the edges to be detected with the optical microscope are generally rougher with every process step. The chrome mask has very defined, practically 2-dimensional features, while the lapped and released nickel parts have rounded edges as shown above, leading to more disparity in measurements. The second effect leading to increase in standard deviation with process step is the fact that PMMA swells during electroplating, leading to linewidth deformation over the length of the arm. This deformation is non-uniform, due to different surrounding geometries of the arm, depending on locations. There will be more comments about PMMA swelling and indications in measurements later in this paper.

\section{Overlay of cloud data with CAD}

Cloud data as the set plotted in Figure 8 is saved using the View microscope and then overlaid with the computer aided design (CAD) part view to ensure the entire contour of the part confirms to the CAD. This data analysis step is performed using a commercially available software package[13]. 


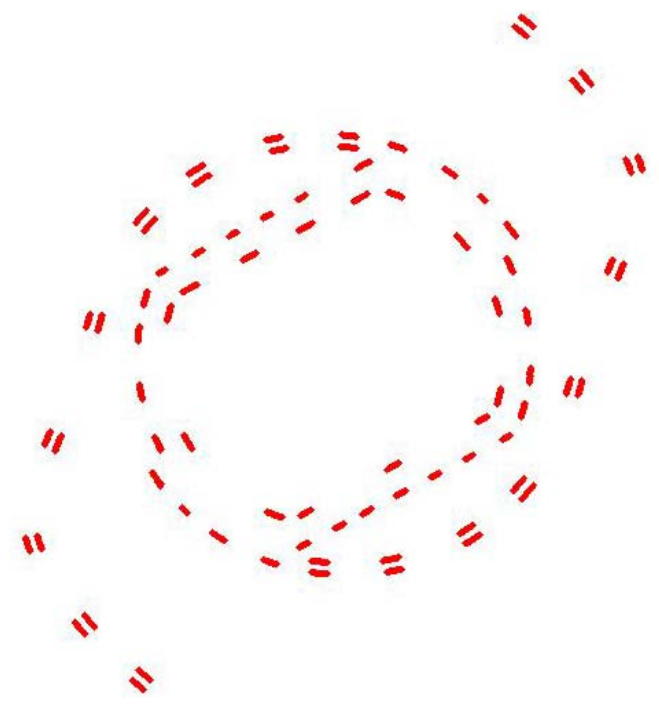

Figure 8: A point cloud of a LIGA spring measured consists of over $\mathbf{4 0 0 0}$ points.

The software allows least squares fits to the entire geometry or datums that can be chosen. Here the center hub is used to align the data to the CAD with a least squares fit. The deviation of the point cloud data from the CAD is visualized by drawing the CAD as a solid model. The point cloud is overlaid and connected to the CAD of the part with socalled „whiskers“ or „spikes“. These are lines drawn from the points normal to the corresponding surface on the CAD, as in Figure 9. The errors seen are multiplied by a factor of twenty. Once the overlay of CAD to data is performed and visualized, the deviations can also be exported and summarized in a histogram. Again, certain geometries of the part can be chosen. Figure 10 shows the histograms for outer surface points on the spring arms. This is data taken on the bottom (released side) of the spring. It is clearly visible that the deviations are within the desired $5 \mu \mathrm{m}$ tolerance.

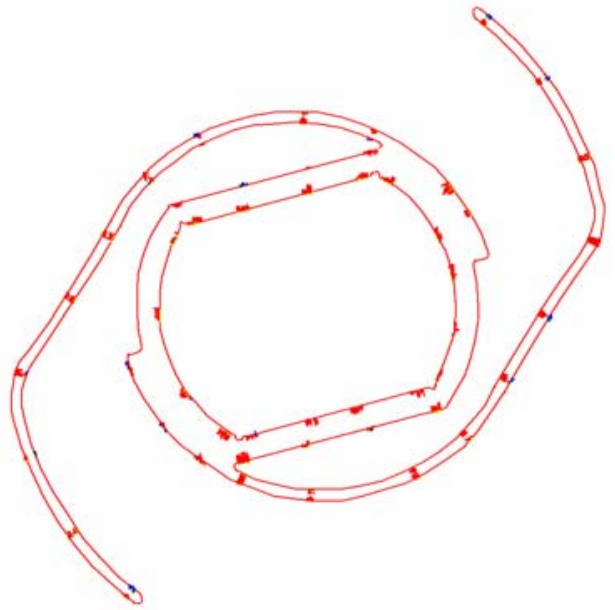

Figure 9: Whiskers plot of point cloud compared to CAD. The cad image CAD is the solid model while the measured points lie in the end point of the whiskers. 

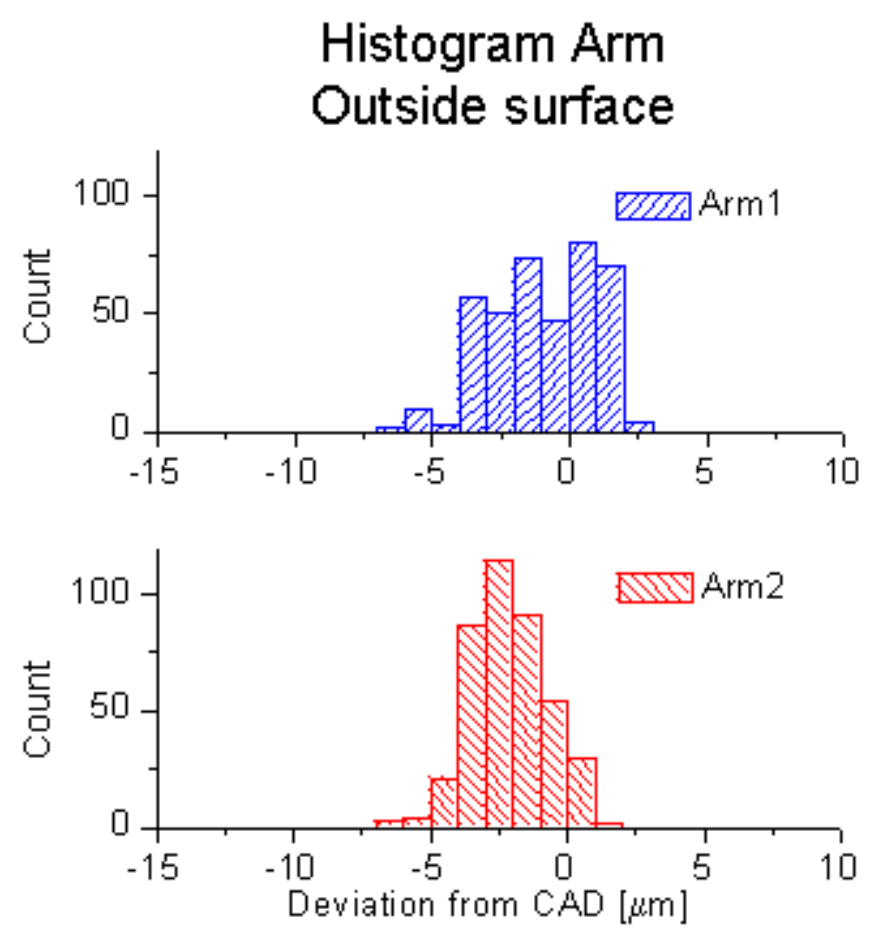

Figure 10: Histogram of measured data deviations from CAD for two arm surfaces.

\section{Large batch examination: PMMA swelling effects}

With many parts inspected identically, large amounts of metrology data are available. Batch processing software was implemented to be able to easily capture and combine large amounts of data. With these tools at hand, many aspects of the process can be examined into detail. For example, typical top and bottom measurements of released springs indicated a noticeable difference between the bottom and top geometries as shown in Figure 11. Focusing on the outside arm surfaces data one a batch of 11 springs, histograms were combined to clearly show the deviation between top and bottom data measured. Figure 12 shows the deviation between top and bottom arm edges on the examined springs. There is a $10.4 \mu \mathrm{m}$ shift between the top data and the well conforming bottom data of the arms. 


\section{Typical bottom} side

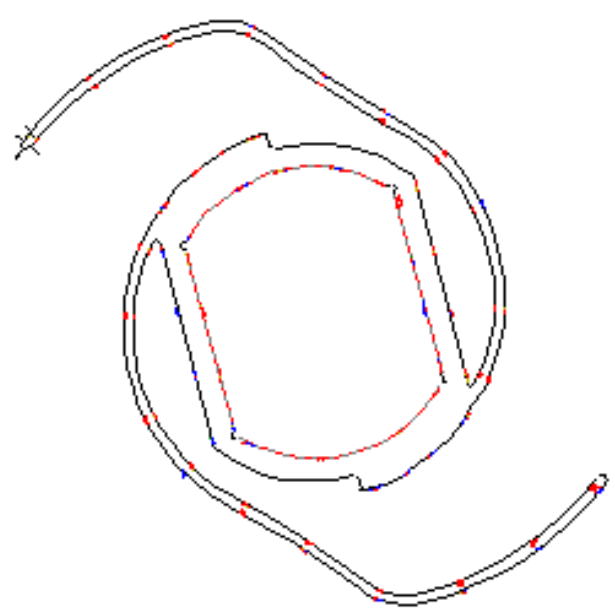

$10 x$ whiskers plot
Typical top side

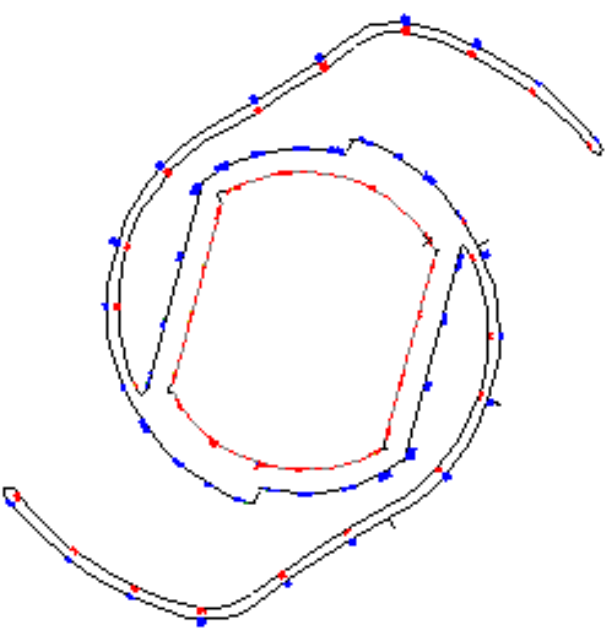

10x whiskers plot

Figure 11: Typical top and bottom side geometries in LIGA springs measured. Note that top topologies are generally slanted out of the part.

\section{Deviation between top and bottom arm edges}

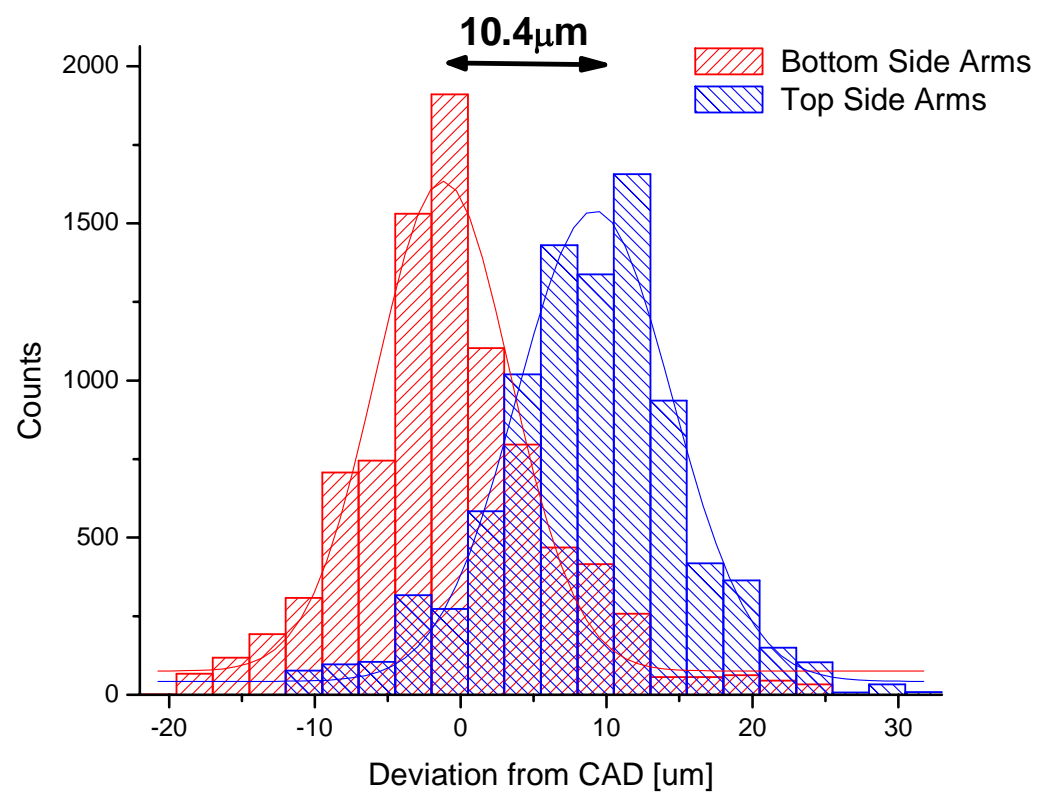

Figure 12: Deviation between the top and bottom arm edge data measured on final parts. 
Responsible for this undesirable skew in the part is the fact that patterned PMMA swells in the electroplating solution $[9,14]$. The swelling can be up to $0.4 \%$, depending on structure height [15]. Arc shapes in PMMA swell non-uniformly from top to bottom, due to substrate boundary conditions as illustrated in Figure 13.

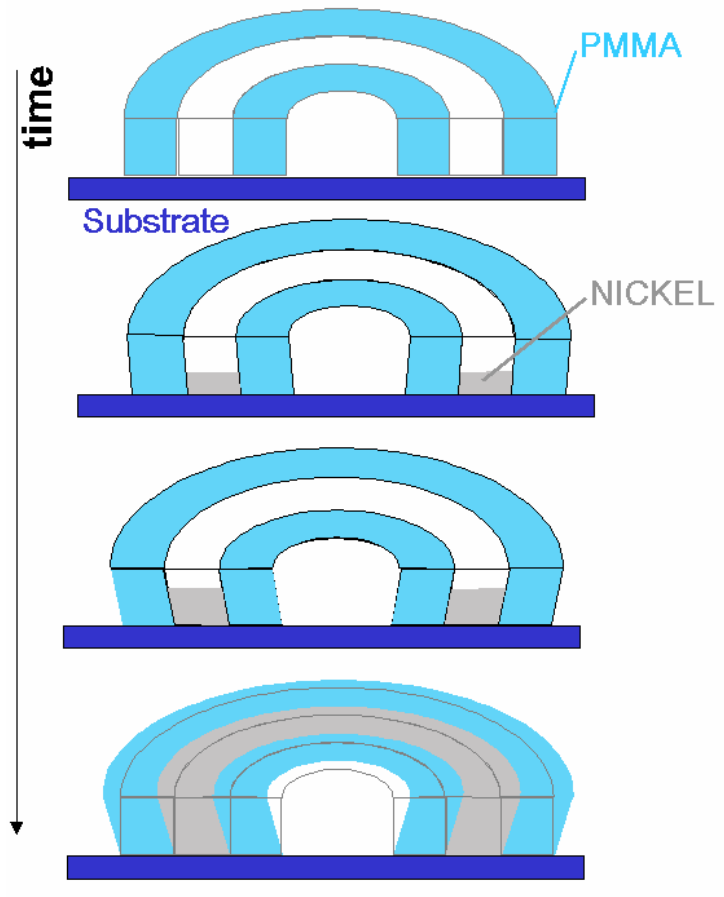

Figure 13: Cut side view showing the evolution of arc geometries during electroplating, starting with a dry mold on top, stopping with a fully electroplated and saturated mold on bottom.

Figure 14 shows the top view of a part in PMMA. There are auxiliary features placed equidistant to the spring arms [14]. The shape created with the auxiliary features is an arc type feature that will swell non-uniformly, moving away from the structure to be defined, as indicated in Figure 14 with arrows. 


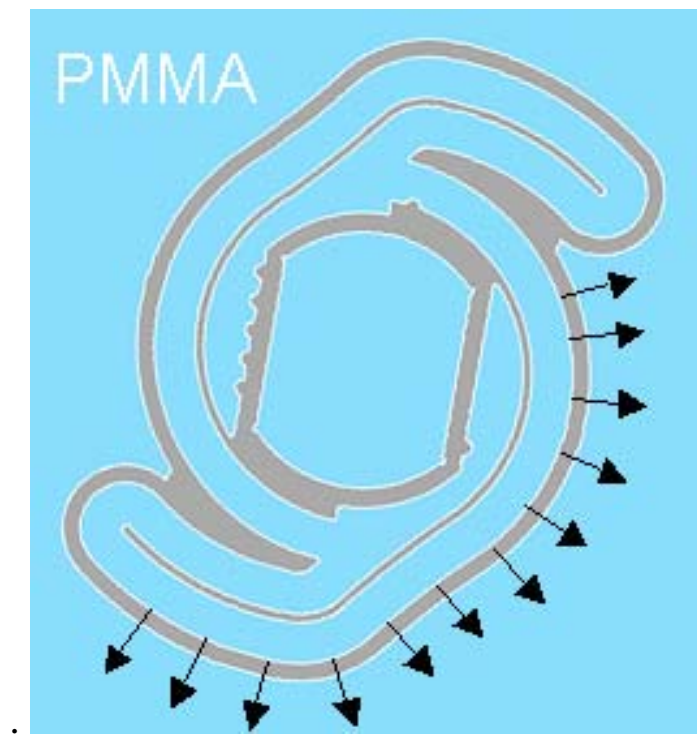

Figure 14 Top view of principal sketch illustrating the swelling of PMMA arcs in part layout [14].

The average displacement of outer arm surface measured was $10.4 \mu \mathrm{m}$. A radius was fitted to the geometry to simplify calculations. FEM simulations for the simplified geometry result in a calculated displacement of $8.2 \mu \mathrm{m}$. The good correspondence between measurement and calculation is encouraging and demonstrates the excellent capability of the metrology acquisition and analysis methods employed.

\section{Summary}

A measuring tool for dimensional metrology on LIGA parts and process steps was defined. Automated measurement processes and data analysis were established and it was shown that the tools are able to handle larger batches of prototype parts. With the tools, it was demonstrated that the process tolerance could be quantified within the process chain. Even on final parts, the metrology capability goes beyond simple inspection and it can be demonstrated that processing effects can be revealed and well quantified as in the example of PMMA swelling. 


\section{References}

1. Becker, E.W., et al., Fabrication of microstructures with high aspect ratios and great structural heights by synchrotron radiation lithography, galvanoforming, and plastic moulding (LIGA process). Microelectronic Engineering, 1986. 4: p. 35-53.

2. Guckel, H., et al., Direct high throughput LIGA for commercial applications: a progress report. Microsystem Technologies, 2000. 6(3): p. 103 - 105.

3. Dearth, B.L. and R.G. Steinhoff, LiGA measurement and acceptance evaluation. Microsystem Technologies, 2003. 9(3): p. 197-203.

4. $\quad$ Achenbach, S., Pantenburg F.-J., Mohr J., Optimierung der Prozessbedingungen zur Herstellung von Mikrostrukturen durch ultratiefe Roentgenlithographie (UDXRL). Wissenschaftliche Berichte, Forschungszentrum Karlsruhe, 2000. FZKA 6576: p. 140.

5. Feiertag, G., et al., Calculation and experimental determination of the structure transfer accuracy in deep x-ray lithography. Journal of Micromechanics and Microengineering, 1997. 7(4): p. 323-331.

6. Mohr, J., W. Ehrfeld, and D. Munchmeier, Requirements on Resist Layers in Deep-etch Synchrotron Radiation Lithography. Journal of Vacuum Science and Technology B, 1988. 6(6): p. 2264-2267.

7. Achenbach, S., J. Mohr, and F.J. Pantenburg, Application of Scanning Probe Microscopy for the determination of the structural accuracy of high aspect ratio microstructures. Microelectronic Engineering, 2000. 53: p. 637-640.

8. $\quad$ Aigeldinger, G., et al., Studying Stacked Ultra Deep X-ray Lithography Exposures: Preliminary Results. Proceedings of the Society of Photo-Optical Instrumentation Engineers (SPIE), 2001. 4557: p. 85-92.

9. Ruzzu, A. and B. Matthis, Swelling of PMMA-structures in aqueous solutions and room temperature Ni-electroforming. Microsystem Technologies, 2002. 8(2-3): p. 116 - 119.

10. Polosky M.A., et al., LIGA Fabricated Environmental Sensing Device. Book of Abstracts, HARMST 1999, Japan, 1999.

11. Dewa, A.S., Mesoscopic systems: bridging from micromachined devices to macroscopic systems. Mechatronics, 1998. 8(5): p. 521-534.

12. View Engineering. Company Homepage: http://www.vieweng.com, Visited 02/04.

13. ICAMP Company web site: http://www.icamp.com, visited 02/04.

14. Griffiths, S.K. and J.A.W. Crowell, Dimensional Errors in LIGA Produced Metal Structures due to Thermal Expansion and Swelling of PMMA. SAND REPORT Sandia National Laboratories, 2004. 2004-8194.

15. Goods, S.H., R.M. Watson, and M. Yi, Thermal Expansion and Hydration Behaviour of PMMA Molding Materials for LIGA Applications1. SAND REPORT, Sandia National Laboratories, 2003(2003-8000). 


\section{Distribution:}

$4 \quad$ Honeywell Federal Manufacturing \& Technologies

Attn: Robert G. Steinhoff

Sherri Huffman

Madhuri Widmar

D. L. Dearth

PO Box 419159

Kansas City, MO 64141

1 Osservatorio Astronomico di Brera

Attn: M. Ghigo

Via E. Bianchi 46,

23807 Merate (LC)

ITALY

1 U.S. Department of Energy

Attn: Craig C. Henderson

NA-115/Forrestal Building

1000 Independence Avenue, SW

Washington, DC 20585

$1 \quad$ MS0196

R. Wild, 2618

$1 \quad$ MS0319

J. R. Fellerhoff, 2610

$1 \quad$ MS0319

D. E. Petersen, 2618

$1 \quad$ MS0319

C. W. Vanecek, 2618

$1 \quad$ MS0437

C.L. Knapp, 2120

$1 \quad$ MS0437

J. M. McGlaun, 2830

1 MS0503

D.W. Plummer 2330

1 MS0561

T. T. Smith 14111

$1 \quad$ MS0889

S. V. Prasad, 1851

$1 \quad$ MS0958

G. L. Benavides 14184

1 MS1007

J. Jones, 15272

1 MS1007

L. Shipers, 15272

MS1310

S. N. Kempka, 9113

1 MS1310

M. A. Polosky, 2614

$1 \quad$ MS9001

M. E. John, 8000; Attn:

MS9004

R. H. Stulen, 8100

MS9007

D. R. Henson, 8200

MS9054

W. J. McLean, 8300

MS9002

P. N. Smith, 8500

MS9003

K. E. Washington, 8900 


$\begin{array}{lll}1 & \text { MS9005 } & \text { B. K. Damkroger, 8240 } \\ 1 & \text { MS9036 } & \text { M. A. Forman, 8245 } \\ 1 & \text { MS9161 } & \text { W. R. Even, 8760 } \\ 1 & \text { MS9403 } & \text { J. M. Hruby, 8700 } \\ 1 & \text { MS9404 } & \text { G. D. Kubiak, 8750 } \\ 1 & \text { MS9401 } & \text { J. E. M. Goldsmith, 8751 } \\ 1 & \text { MS9401 } & \text { M. A. Hekmaty, 8751 } \\ 1 & \text { MS9401 } & \text { L. L. Hunter, 8751 } \\ 1 & \text { MS9401 } & \text { K. D. Krenz, 8751 } \\ 1 & \text { MS9401 } & \text { M. E. Malinowski, 8751 } \\ 1 & \text { MS9401 } & \text { S. Mrowka, 8751 } \\ 5 & \text { MS9401 } & \text { D. M. Skala, 8751 } \\ 1 & \text { MS9401 } & \text { A. A. Talin, 8751 } \\ 15 & \text { MS9401 } & \text { G. Aigeldinger, 8753 } \\ 1 & \text { MS9401 } & \text { D. R. Boehme, 8753 } \\ 1 & \text { MS9401 } & \text { G. F. Cardinale, 8753 } \\ 5 & \text { MS9401 } & \text { J. T. Ceremuga, 8753 } \\ 1 & \text { MS9401 } & \text { J. T. Hachman, 8753 } \\ 1 & \text { MS9401 } & \text { J. J. Kelly, 8753 } \\ 1 & \text { MS9401 } & \text { D. E. McLean, 8753 } \\ 1 & \text { MS9401 } & \text { T. I. Wallow, 8753 } \\ 1 & \text { MS9401 } & \text { P. C. Y. Yang, 8753 } \\ 1 & \text { MS9042 } & \text { G. H. Evans, 8752 } \\ 1 & \text { MS9042 } & \text { S. K. Griffiths, 8752 } \\ 1 & \text { MS9042 } & \text { R. S. Larson, 8752 } \\ 1 & \text { MS9042 } & \text { C. D. Moen, 8752 } \\ 1 & \text { MS9042 } & \text { R. H. Nilson, 8752 } \\ 1 & \text { MS9042 } & \text { A. Ting, 8752 } \\ 1 & \text { MS9403 } & \text { L. A. Domeier, 8762 } \\ 1 & \text { MS9403 } & \text { B. E. Mills, 8773 } \\ 1 & \text { MS9403 } & \text { A. M. Morales, 8762 } \\ 1 & \text { MS9403 } & \text { N. Y. C. Yang, 8773 } \\ 1 & \text { MS9405 } & \text { K. L. Wilson, 8770 } \\ 1 & \text { MS9409 } & \text { J. R. Garcia, 8754 } \\ 1 & \text { MS9409 } & \text { S. H. Goods, 8754 } \\ 1 & \text { MS9409 } & \text { J. S. Korellis, 8754 } \\ 1 & \text { MS9409 } & \text { W.Y. Lu, 8754 } \\ 3 & \text { MS9018 } & \text { Central Technical Files, 8945-1 } \\ 1 & \text { MS0899 } & \text { Technical Library, 9616 } \\ 1 & \text { MS9021 } & \text { Classification Office, 8511, for Technical Library, MS0899, 9616 } \\ & & \\ & & \text { DOE/OSTI via URL } \\ & \end{array}$

DOE/OSTI via URL 
This page intentionally left blank.- 